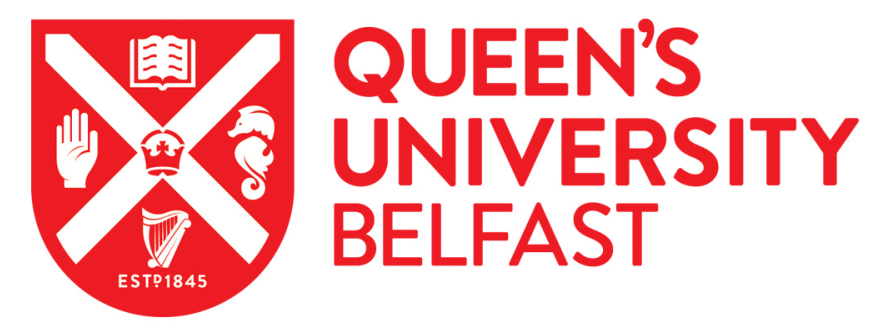

\title{
Neighborhood-Based Differences in Walkability, Physical Activity, and Weight Status in India
}

Adlakha, D., Hipp, J. A., \& Brownson, R. C. (2016). Neighborhood-Based Differences in Walkability, Physical Activity, and Weight Status in India. Journal of Transport and Health, 3(4), 485-499.

https://doi.org/10.1016/j.jth.2016.10.008

Published in:

Journal of Transport and Health

Document Version:

Peer reviewed version

Queen's University Belfast - Research Portal:

Link to publication record in Queen's University Belfast Research Portal

\section{Publisher rights}

Copyright 2017 Elsevier.

This manuscript is made available under a Creative Commons Attribution-NonCommercial-NoDerivs License

(https://creativecommons.org/licenses/by-nc-nd/4.0/), which permits distribution and reproduction for non-commercial purposes, provided the author and source are cited.

\section{General rights}

Copyright for the publications made accessible via the Queen's University Belfast Research Portal is retained by the author(s) and / or other copyright owners and it is a condition of accessing these publications that users recognise and abide by the legal requirements associated with these rights.

Take down policy

The Research Portal is Queen's institutional repository that provides access to Queen's research output. Every effort has been made to ensure that content in the Research Portal does not infringe any person's rights, or applicable UK laws. If you discover content in the Research Portal that you believe breaches copyright or violates any law, please contact openaccess@qub.ac.uk. 


\section{Neighborhood-Based Differences in Walkability, Physical Activity, and Weight Status in India}

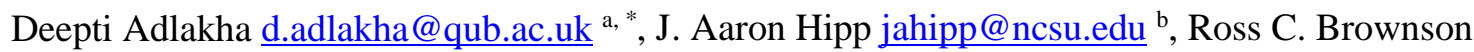
rbrownson@wustl.edu $^{\text {a, c }}$

${ }^{a}$ Center for Public Health, School of Medicine, Dentistry and Biomedical Sciences, Queen’s University Belfast, United Kingdom

${ }^{\mathrm{b}}$ Department of Parks, Recreation, and Tourism Management, Center for Geospatial Analytics, Center for Human Health and the Environment, North Carolina State University, Raleigh, NC 276958004, USA

${ }^{\mathrm{c}}$ Brown School, Prevention Research Center in St. Louis, Division of Public Health Sciences and Siteman Cancer Center, Washington University, School of Medicine, Washington University in St. Louis, St. Louis, MO 63130, USA

*Corresponding Author:

Deepti Adlakha, PhD, MUD

Center for Public Health

School of Medicine, Dentistry and Biomedical Sciences Queens University-Belfast

United Kingdom

Email: d.adlakha@qub.ac.uk

Phone: +44-2890-976431

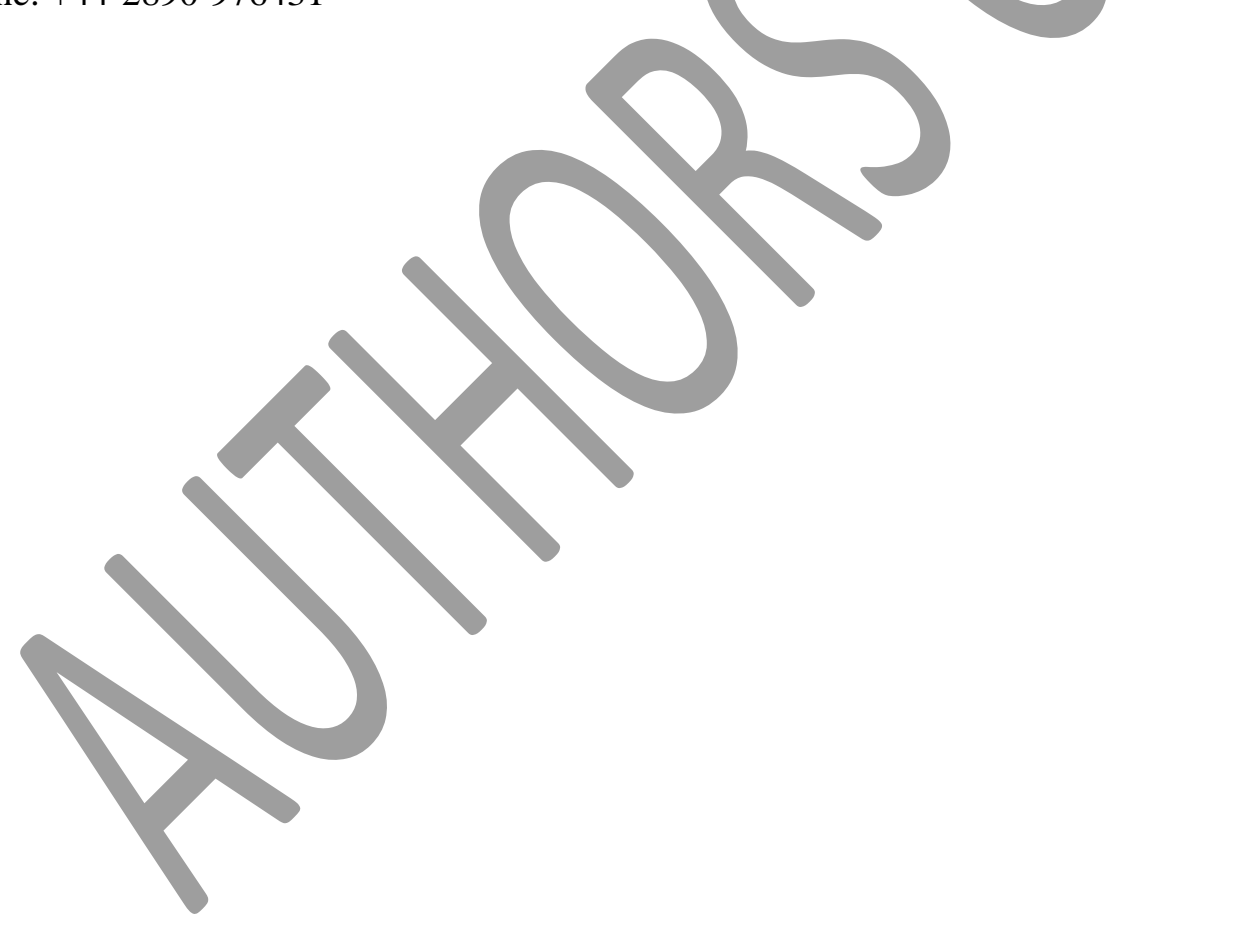




\section{Highlights}

1. First to document differences in built environment and physical activity in India.

2. Transport-related physical activity was more predominant among low-SES populations.

3. High-SES populations reported greater leisure-time physical activity.

4. High-SES populations reported longer sitting time and higher BMI.

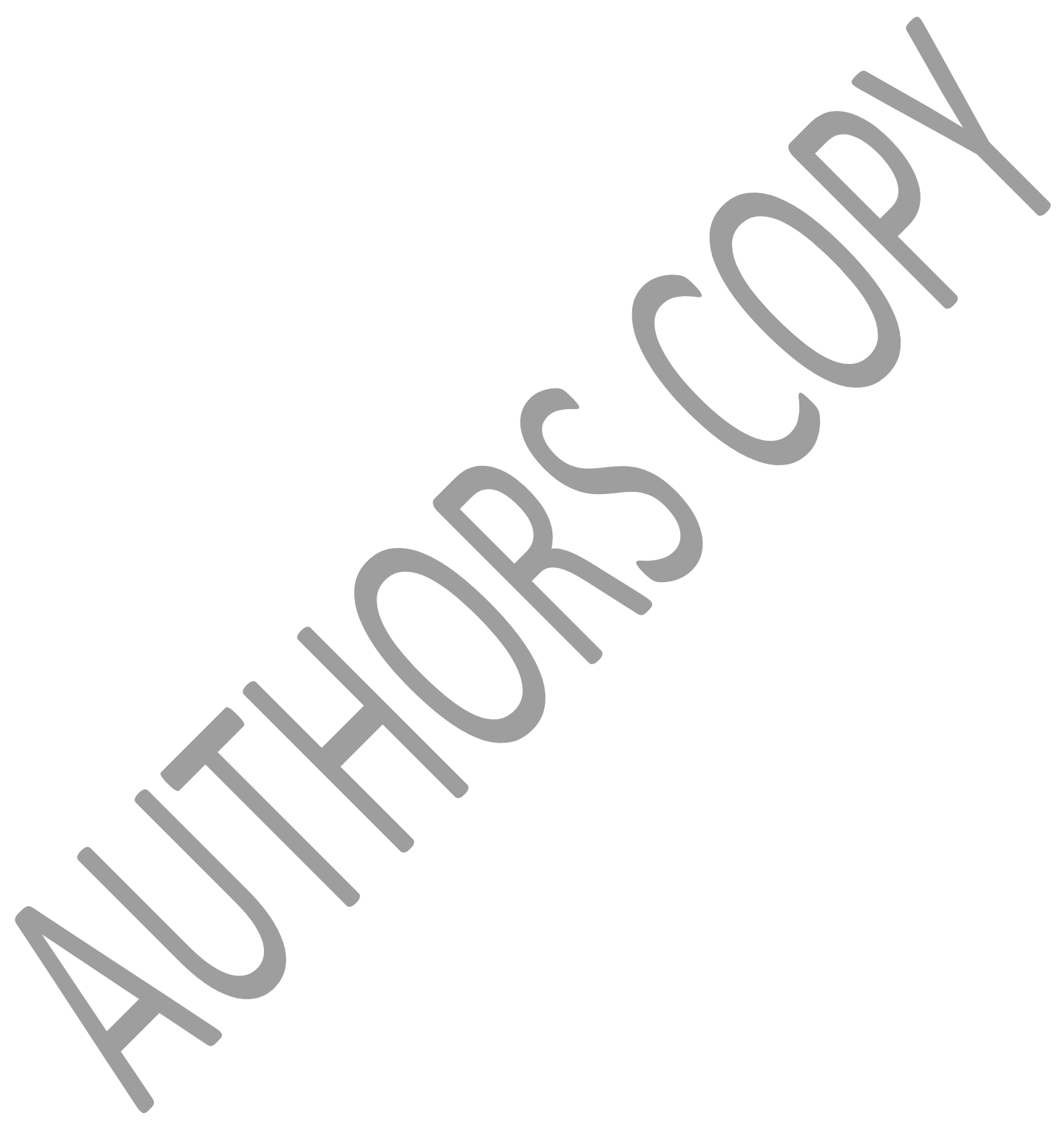




\begin{abstract}
Introduction

Data on built environment (BE) and physical activity (PA) in low- and middle- income countries is sparse. This study compared BE features, PA levels, and weight status among adults living in neighborhoods stratified by walkability and socio-economic status (SES) in the city of Chennai, India.
\end{abstract}

\title{
Methods
}

This cross sectional study design surveyed 370 adults ( $\geq 18$ years) from four neighborhoods with differing walkability and socio-economic status. Participants were asked to complete a survey on their neighborhood environment, leisure and travel PA, height, weight, and demographic characteristics. Oneway analysis of variance tests were used to examine differences across neighborhoods.

\section{Results}

Residents of high-walkability/high-SES neighborhoods reported higher land use mix diversity, land use mix access, street connectivity, aesthetics, and safety from crime. Residential density and walking/bicycling infrastructure were highest in the high-walkability/low-SES neighborhood. Transport PA was the maximum contributor to total PA in low-SES neighborhoods, while residents of high-SES neighborhoods reported greater levels of leisure-time PA. Sitting time and BMI were greater among highSES participants. Patterns of PA, sedentary time, and weight status varied significantly by neighborhood walkability and SES.

\section{Conclusions}

An understanding of BE correlates of domain-specific PA can support the development of contextually tailored interventions to promote physical activity and reverse the determinants of inactivity occurring through patterns of urbanization and sedentary behaviors in India.

\section{Keywords}

India; walkability; physical activity; sedentary behavior; body mass index; non-communicable diseases 


\section{Introduction}

India, with a population of 1.2 billion people and will soon be the world's most populous country. ${ }^{1}$ India is experiencing a non-communicable disease (NCD) epidemic. ${ }^{2-5}$ Rapid rates of increase of obesity, diabetes mellitus, and associated chronic and co-morbid NCDs (e.g., cardiovascular diseases and some cancers) are being documented in India, yet in-country evidence-based research is lacking. ${ }^{2,}{ }^{6}$ Currently, India has the largest diabetic population with 33 million, projected to reach 100 million by $2020{ }^{7}$ Cardiovascular disease is the leading cause of death in India, and its contribution to mortality is rising; deaths due to cardiovascular disease are projected to double between 1985 and 2015..$^{7-9}$ Morbid obesity is currently affecting $5 \%$ of Indians (approximately 61 million people). ${ }^{10}$ Despite such alarming statics, there is minimal research examining the rising prevalence and risk factors causing NCDs in the general population of India.

Calls to reduce global epidemics of NCDs by the United Nations and the World Health Organization have recommended increasing physical activity (PA) as a key strategy. ${ }^{71-13}$ Environmental and policy supports for increasing PA (e.g., walking, bicycling) represent promising modifiable strategies to curb the rise in NCDs at a population level. ${ }^{14}$ Understanding the associations between PA and the neighborhood built environment (BE) where the activity occurs has been the subject of recent international interest. ${ }^{15,16}$ This interest reflects a social ecological view of health ${ }^{17,18}$ and recognition of the interaction between individuals and their environment.

In the developed countries of North America, Australia, and Europe, consistent findings have emerged that BE features can facilitate or constrain PA. ${ }^{19-28}$ For example, measures of land-use mix, residential density, and street intersection density have been positively related to minutes of moderate PA per day. Presence of sidewalks, bicycle lanes, bus shelters, and access to public transportation (e.g., bus rapid transit, light rail) has been linked to increased levels of transport PA. ${ }^{23}{ }^{29}$ Studies have demonstrated that individuals in more walkable, mixed-use, and transit accessible neighborhoods tend to walk or bicycle more and have a lower likelihood of obesity compared with those in automobile-dependent neighborhoods. ${ }^{29-32}$ In addition to walking, other exercise activities, BMI, and overall health ratings, neighborhood design can also influence air pollution emissions and exposures, thus impacting several chronic disease outcomes (e.g., cardiovascular disease, asthma and other respiratory ailments). ${ }^{33,34}$ However, these relationships established in developed countries may not generalize to other parts of the world, particularly in low-and-middle-income countries (LMICs) like India that are collectively home to $80 \%$ of the world's population and are at particularly higher risk for developing NCDs. ${ }^{6,35,36}$ Questions also remain about the applicability of surveys constructed in developed countries to the local contexts in LMICs. To address this issue, there have been recent calls for investigators to collaborate on a regional basis to adapt BE measures that are tailored to the LMIC contexts. ${ }^{37,38}$

India is experiencing dramatic urban growth with implications for social, economic, and ecological sustainability. ${ }^{39,40}$ Urbanization has outpaced the development of basic public health services and regional infrastructure, compounding health threats from NCDs. ${ }^{40,41}$ Along with poor chronic health outcomes, issues of pedestrian safety, air pollution, and increasing carbon emissions are especially challenging to adapt to in urban environments already facing disparities across religious and socio-economic lines. ${ }^{42-45}$ While the consequences of urban living may be exposed through a population's health, the underlying 
causes or amplifications of health problems are often rooted in conditions best addressed through nonpublic health pathways such as neighborhood design and planning, as explored in this study.

To our knowledge, there is no literature that documents relations between neighborhood walkability, BE variables, and PA in India. ${ }^{2}$ Studies on active transportation in India are minimal, and do not provide definitive explanations. From a PA and public health perspective, these transportation studies have numerous shortcomings: the contribution of community design to overall PA is unknown, neighborhood environment variables have not been studied, and reliable and valid measures of environmental variables tailored to the Indian context have not been used in these studies. Further investigation of the environmental correlates of PA is needed and could lead to improved interventions for Indian contexts.

This paper probes the question of how the BE, including density, land-use mix, and elements of design (e.g. pedestrian and bicycling facilities), pedestrian safety, and crime influence walking, bicycling, and PA behaviors. We use a self-report measure of neighborhood environment adapted for IndiaNeighborhood Environment Walkability Scale ${ }^{46,47}$ (hereafter called NEWS-India)-and its variables hypothesized to be important contributors to PA. We compare PA and weight status among adult residents living in neighborhoods stratified by walkability and socio-economic status (SES).

\section{Methods and Analysis}

\subsection{Study Setting}

This study recruited a diverse sample of participants from the metropolitan area of the city of Chennai, India (164.5 sq. miles). Chennai is the capital city of the state of Tamil Nadu, a major commercial and industrial hub in southern India. ${ }^{48,49}$ It is the fourth most populous city (8.9 million residents) in India and the $31^{\text {st }}$ most populous city in the world. ${ }^{50}$ Within India, the state of Tamil Nadu is the most urbanized state with 48.4 percent of the population living in urban areas ${ }^{51}$ and has the highest number of diabetic cases, a majority of them being reported in the city of Chennai. ${ }^{52}$ For administrative purposes, the Chennai metropolitan area is divided into 155 smaller subdivisions called wards. Wards are the smallest geographic areas for which the Census Bureau of India publishes demographic information. Due to the lack of consensus on what constitutes a neighborhood, ${ }^{53}$ wards were used as the primary definition and unit for sampling purposes.

\subsection{Sampling}

This study adopted a stratified two-stage cluster sampling strategy. Study participants were selected from neighborhoods chosen to maximize the variance in neighborhood walkability and SES. ${ }^{54}$ This type of stratification by SES was used to enhance the representativeness of the sample because low-SES populations tend to be underrepresented in studies of this nature. ${ }^{55,56}$ The goal of this study design was to select participants from neighborhoods stratified into four quadrants that represent the following criteria: high-walkable/high-SES, high-walkable/low-SES, low-walkable/high-SES, and low-walkable/low-SES.

The sampling protocol used in this study is based on the recommendations of the International Physical activity and the Environment Network (IPEN; www.ipenproject.org), an organization that has established common methods and measures for worldwide research on PA and BE's. A major goal of IPEN is to represent the worldwide variation in BE's. Previous IPEN studies of this nature have used GIS-based walkability indices to operationalize walkability. ${ }^{57}$ To stratify neighborhoods by SES, IPEN studies have 
used median household income obtained from appropriate government ministries, departments or agencies. ${ }^{38,57}$ Due to the lack of ward-level GIS and household income data for the city of Chennai, WalkScore ${ }^{58}$ was used to classify neighborhoods based on walkability and cost of rental units per square foot to define ward-level SES.

Neighborhoods (wards) were divided into ten equal groups (deciles) based on their walkability and SES levels. Neighborhoods in deciles 1, 2, 9, 10 were omitted to avoid outliers. Neighborhoods in deciles 5 and 6 were excluded to create separation between the categories. Neighborhoods in deciles 3, 4 (low walkability) and 7, 8 (high walkability) were selected for potential participant recruitment.

Neighborhoods were also divided into deciles by SES and the neighborhoods in deciles 3, 4 (low-income) and 7, 8 (high income) were selected for participant recruitment.

\subsection{Participant Recruitment}

Participants were recruited from identified neighborhoods using a purposive sampling technique. The research team formerly established relationships with city government departments (Chennai Metropolitan Development Authority, Chennai Traffic Police, and Commissioner of Police), non-profit organizations (Chennai City Connect, Transparent Chennai, Institute for Transportation and Development Policy), neighborhood associations, resident welfare groups, and other local community organizations to assist in creating awareness about the study in the neighborhood and facilitating the recruitment process. These relationships were used to establish contact with a small pool of residents in selected neighborhoods. These residents, through their social networks, suggested other residents who were interested in participating in the study.

Participants were contacted either in-person, via telephone or email, with up to 6 contact attempts to assess study interest and eligibility. Inclusion and exclusion criteria for participants were based on IPEN protocol and studies conducted in Nigeria ${ }^{38}$, Brazil, ${ }^{59}$ and China. ${ }^{60}$ Eligibility criteria for local residents included: (i) current residents of the Chennai metropolitan area; (ii) residents for at least 6 months; (iii) 18-65 years of age; (iv) being able and willing to answer questions in English or Tamil, which is the official language in the study region; (v) not having any disability that prevented independent walking; and (vi) no visible signs of cognitive impairment. One individual per household was recruited to ensure independence of observations. In order to ensure selection of a diverse sample, effort was made to recruit residents from different neighborhoods across the Chennai metropolitan area that matched the walkability and SES selection. Data collection occurred between December 2014 and April 2015.

Sample size was determined using a moderate-to-large effect size (effect size statistic $[d=]$ 0.75), which is greater than what has been used in previous IPEN studies in LMIC contexts. ${ }^{38,61}$ We determined that 73 participants from each of the four neighborhood quadrants — high-walkable/high-SES, high-walkable/lowSES, low-walkable/high-SES, and low-walkable/low-SES - were needed to detect a moderate-to-large effect size with more than $80 \%$ power. ${ }^{62}$ Recruitment continued until approximately 75 individuals from each neighborhood had completed the surveys.

The first author made initial contact with participants to provide introductory information about the study, explain study procedures, and obtain verbal consent. Participants were given the choice of completing the surveys in English or Tamil. Trained bilingual research assistants administered the surveys to eligible and 
interested participants. All study procedures were approved by the Institutional Review Board at Washington University in St. Louis.

\subsection{Measures}

\subsubsection{Neighborhood Environment Walkability Scale-India (NEWS-India)}

The Neighborhood Environment Walkability Scale (NEWS) is the most frequently used questionnaire for assessing perceived attributes of the neighborhood environment for PA worldwide. ${ }^{46,57,63}$ IPEN has used NEWS as an instrument to evaluate cross-country analyses of BE and PA relationships. ${ }^{64}$ It is a reliable and valid instrument that has been tested internationally and translated into many languages. ${ }^{56,57,63,65,66}$ An adapted version of NEWS for the Indian context (NEWS-India) was used to measure BE characteristics across the four neighborhood quadrants in Chennai. The adaptation of the NEWS was conducted by Indian and international experts, and final items were selected for NEWS-India after cognitive response testing and evaluation of its reliability and validity. NEWS-India was translated into Tamil by a knowledgeable bilingual translator, reviewed by an expert panel to ensure its conceptual relevance, and back-translated into English. Details of NEWS-India development, cultural adaption, and test-retest reliability have been described elsewhere. ${ }^{67}$

The adapted NEWS-India consisted of 91 items that assessed the following perceived BE characteristics: a) residential density (7 items); b) proximity to non-residential land uses (land use mix - diversity; 43 items); ease of access to non-residential uses (land use mix - access; 4 items); street connectivity (3 items); infrastructure and safety for walking and cycling (12 items); aesthetics (6 items); traffic safety (6 items) and safety from crime (4 items). Six other items were analyzed as single items: parking is difficult near local shopping areas; streets in the neighborhood are hilly; streets in the neighborhood do not have many dead-ends; major barriers to walking in my neighborhood that make it difficult to walk (e.g., bad roads, poor sidewalks, water logging); I see and speak to other people while walking in the neighborhood; there are walking paths in my neighborhood that connect dead-ends to main roads or streets. Subscales and sample NEWS-India items are presented in Table 1. Scoring details and a digital version of the original NEWS can be found on http:// sallis.ucsd.edu/measures.

All subscales and single items, with the exception of residential density and land use mix-diversity, were rated on a 4-point Likert scale ranging from 1 (strongly disagree), 2 (somewhat disagree), 3 (somewhat agree) to 4 (strongly agree). Residential density items asked about the presence of various types of neighborhood residences, from single-family homes to 13-story or higher apartments/ flats, with a response range of 1 (none) to 5 (all). Residential density items were weighted relative to the average density of single-family residences (e.g., 7- to- 12 story apartments were considered to be 50 times more person-dense than single family residences), and weighted values were summed to create a residential density subscale score. ${ }^{61,68}$ Land use mix diversity was assessed by the walking proximity from homes to various types of destinations, with response ranging from 1- to 5-minutes walking distance (coded as 5) to $>30$ minutes walking distance (coded as 1 ). Higher scores on land use mix-diversity indicated closer average proximity implying higher walkability. Scoring of subscales, aggregate NEWS-India score, and selection of the single items were based on methods proposed by Cerin et al. ${ }^{56}$

\subsubsection{International Physical Activity Questionnaire (IPAQ)}

The leisure and transport modules from the long version of the International Physical Activity 
Questionnaire (IPAQ-long) were used to assess participants' self-reported PA. ${ }^{69}$ The questionnaire assessed frequency (number of days in the last 7 days) and duration (hours and minutes per day) of PA in two domains (transportation and recreation). The IPAQ was used to compute weekly minutes of walking for transport and leisure, bicycling for transport, and moderate-to-vigorous PA (MVPA). Leisure time MVPA was obtained by summing minutes per week of moderate PA and vigorous PA during leisuretime. Total MVPA was computed by summing the total minutes/week of reported PA of moderate and vigorous intensities across the two domains. For total PA, the total minutes/ week of activities in each domain were summed (total transport + total leisure-time minutes/week scores) to gain an overall estimate of PA in a week (www.ipaq.ki.se). A question on daily time spent sitting (sedentary time) was asked from IPAQ-short version. The IPAQ has good reliability (intra-class correlations range from 0.46 to $0.96)$ and fair-to-moderate criterion validity in a 12-country study $(\rho=0.30)$, comparable to other selfreport measures. ${ }^{70}$ Acceptable intra-class correlation coefficients ranging from 0.60 to 0.82 have been reported for the transportation and leisure-time PA modules of IPAQ. ${ }^{7}$

\subsubsection{Demographic Variables and Weight Status}

Information on age, gender, marital status, religion, income, educational level, and employment status were elicited from the participants. Marital status was classified as married and not married. Educational level was classified as uneducated, primary-middle school, high school or diploma, and graduate or professional. Employment status was classified into unemployed (homemaker, student, retired, or unable to work), blue collar, or white collar. Income was categorized into 4 groupings based on Indian Rupees/month (1 Indian Rupee = approx. 0.016 US Dollars).

Participants were asked to self-report height and weight. Body mass index (BMI) was calculated as body weight divided by the square of height $\left(\mathrm{kg} / \mathrm{m}^{2}\right)$. The World Health Organization principal cutoff points for BMI were used to create the categories: underweight $\left(<18.5 \mathrm{~kg} / \mathrm{m}^{2}\right)$, normal weight $\left(18.5-24.99 \mathrm{~kg} / \mathrm{m}^{2}\right)$, overweight (25-24.99 kg/m²), and obese $\left(\geq 30 \mathrm{~kg} / \mathrm{m}^{2}\right){ }^{11}$

\subsection{Data Analysis}

The purpose of the data analyses was to determine differences in BE characteristics, PA levels, and weight status by neighborhood quadrants. Demographic characteristics of the sample were compared across neighborhood quadrants using one-way Analysis of Variance (ANOVA) tests for continuous variables, and with chi-square tests for nominal variables. Descriptive statistics of all participants are presented in Table 2.

Data on BE and PA levels was evaluated for normality and for potential outliers. Individuals with extremely high PA values were eliminated from the analyses following IPAQ scoring guidelines. ${ }^{69}$ All cases in which the sum total of all walking, moderate and vigorous time PA was greater than 960 minutes per day (16 hours) were excluded from the analysis. This assumes that on average 8 hours per day is spent sleeping by an individual. ${ }^{69}$

Self-reported walking scores had high positive kurtosis and positive skewness; thus, logarithmic transformations were used in analyses. Perceived BE data were neither highly skewed nor kurtotic; these data were not transformed. Mean values are presented in Tables 3 and 4. Multiple linear regression models were used to determine overall differences in NEWS-India scores, domain-specific PA levels, 
sedentary time, and BMI, controlling for demographic variables and car ownership. Differences in NEWS scores across neighborhoods are presented in Table 3. Neighborhood differences in PA (travel, leisure, and total), sedentary (sitting) time, and weight status (Body Mass Index) are presented in Table 4. Analyses were conducted using the Statistical Package for the Social Sciences (SPSS) version 22. ${ }^{72}$

\section{Results}

\subsection{Descriptive Statistics}

The total sample comprised 370 participants with $54.2 \%$ females and mean age of $37.9 \pm 15.3$ years (Table 2). The majority of participants were married (61.2\%) and employed (62.5\%), either in blue collar (31.4\%) or white collar jobs (31.1\%). About 13\% of participants were uneducated, $21.5 \%$ of participants had a high school education or equivalent, while $49.7 \%$ had a graduate or professional degree. Income levels reported 48.2\% earning less than 36,017 Indian rupees (approximately 600 US Dollars) per month. Significant differences in demographic characteristics across all neighborhood quadrants were observed.

\subsection{Neighborhood Characteristics}

Table 3 shows that the high-walkability/high-SES neighborhood had higher scores on five of the eight NEWS subscales: land use mix diversity, land use mix access, street connectivity, aesthetics, and safety from crime. Highest residential density (weighted mean $=866.9$ per sq.km.) and walking/bicycling infrastructure (mean $=2.2$ ) was reported in the high-walkability/low-SES neighborhood. Safety from traffic (mean $=2.5$ ) was greatest in the low walkability/low SES neighborhood. Overall, highwalkability/high-SES neighborhood reported the highest NEWS score (mean $=19.8$ ) while the lowest NEWS score was found in low-walkability/low-SES neighborhood (mean =14.6). Except for walking/cycling facilities, significant differences were observed for all NEWS subscales and single items scores across the four quadrants. NEWS subscale scores, single item scores, and differences across neighborhoods are listed in Table 3.

Figure 1. Photographs of high walkability neighborhoods in Chennai, India.
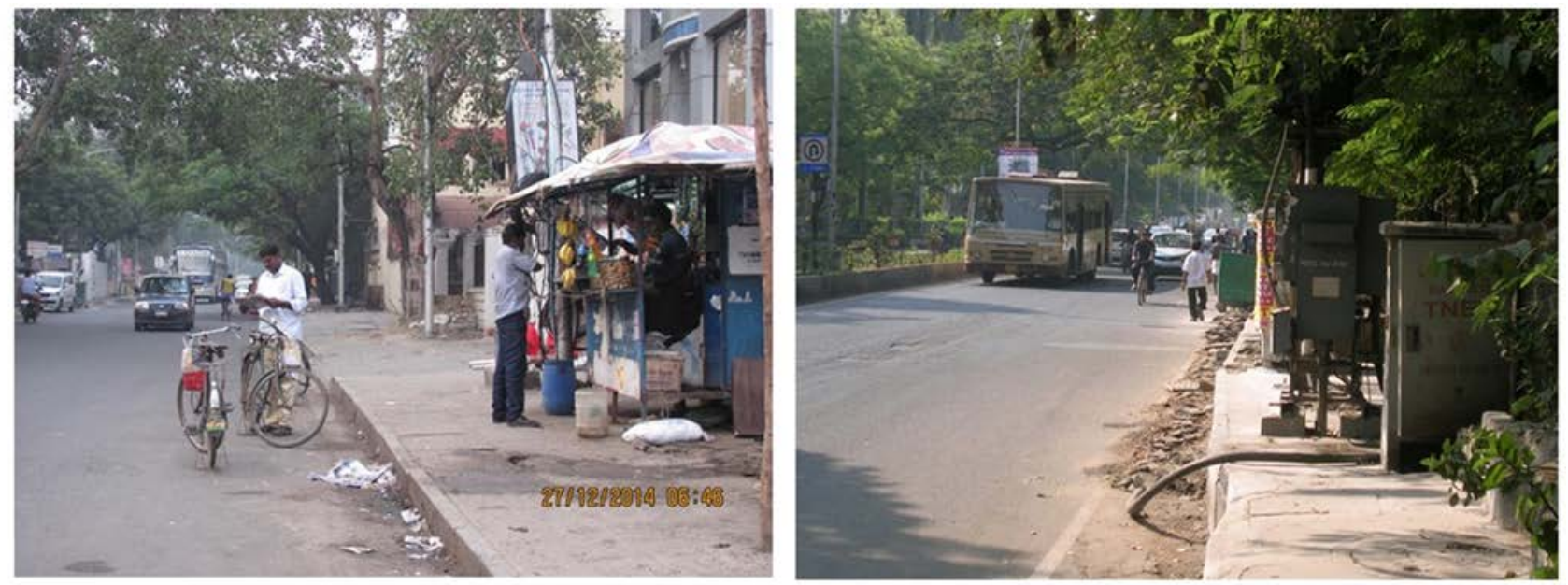
Figure 2. Photographs of low walkability neighborhoods in Chennai, India.
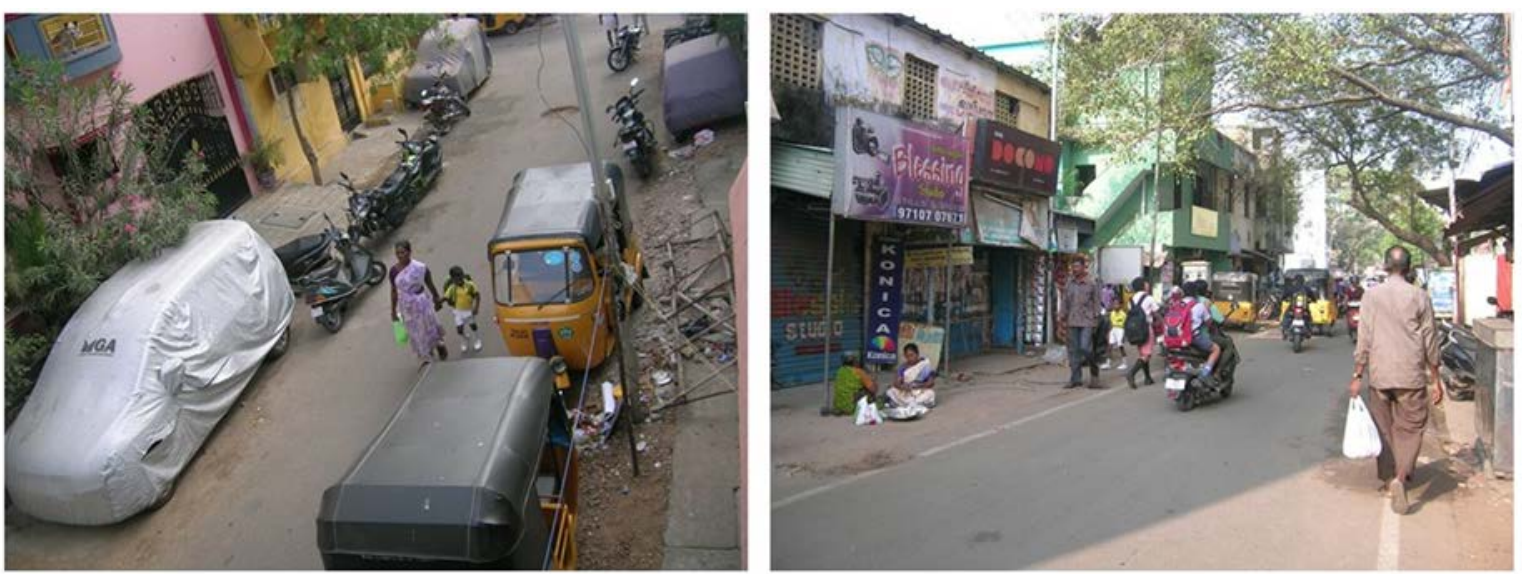

\subsection{Transport Physical Activity}

Comparing the high-walkability neighborhoods, higher levels of transport PA were observed in the lowSES neighborhood. Residents of low-SES neighborhoods (quadrants 3, 4) reported higher levels of walking, bicycling, and total transport PA compared to residents of high-SES neighborhoods (Table 4). A similar pattern exists in the low-walkability neighborhoods-residents in the low-SES neighborhood engaged in approximately 126 and 61 more minutes of transport-related walking and bicycling per week respectively, than their counterparts in the high-SES neighborhood. Residents in the low walkability/low SES neighborhood reported the most number of minutes of walking (223 minutes per week approximately) and bicycling (75 minutes per week approximately) for transport purposes during the past 7 days compared to residents of the other neighborhoods. Overall, total transport PA was highest among residents of the low-walkability/low SES neighborhood (275 minutes per week) and lowest among residents of the high-walkability/high SES neighborhood (28 minutes per week). Results from linear regression models show significant differences in levels of transport-related walking $(F=10.0, p<.001)$, bicycling $(\mathrm{F}=8.4, \mathrm{p}<.001)$, and total transport PA $(\mathrm{F}=12.0, \mathrm{p}<.001)$ between the neighborhoods.

\subsection{Leisure Physical Activity}

Leisure-time walking was highest among residents of the high-walkability/low-SES neighborhood (quadrant 3) with a mean value of approximately 129 minutes in the past 7 days. Lowest leisure-time walking levels were reported by residents of the low-walkability/high-SES neighborhood (quadrant 2) with a mean value of approximately 50 minutes in the past 7 days. There were significant differences in leisure-time walking across the four neighborhoods $(\mathrm{F}=5.8, \mathrm{p}<.001)$.

Significant differences were observed in leisure-time Moderate-to-Vigorous PA (MVPA; includes only leisure-time moderate and vigorous PA) across neighborhoods $(F=6.8, \mathrm{p}<.001)$. High- SES residents in low walkable neighborhoods reported highest levels of leisure-time MVPA per week (147 minutes), followed by high-SES residents in high walkable neighborhoods (129 minutes per week). In the low-SES 
quadrants, residents in low walkable neighborhoods had the least engagement in leisure-time MVPA (42 minutes per week).

Overall, total levels of leisure-time PA (LTPA; includes leisure-time walking and leisure-time MVPA) followed a pattern similar to leisure-time MVPA. Significant differences were observed in LTPA across neighborhoods $(\mathrm{F}=5.0, \mathrm{p}<.001)$. High-SES residents in high walkable neighborhoods reported highest levels of LTPA per week (221minutes), followed by high-SES residents in low walkable neighborhoods (202 minutes per week). In the low-SES quadrants, residents in low walkable neighborhoods had the least engagement in LTPA (111 minutes per week).

\subsection{Total Physical Activity}

Total weekly levels of MVPA and all PA (including walking and bicycling) were highest in the lowwalkability/low-SES neighborhood (quadrant 4), at approximately 288 and 358 minutes, respectively. Lower MVPA (157 minutes) and all PA (249 minutes) was reported in the high-walkability/high-SES neighborhood. Significant differences in MVPA between neighborhood groups were observed ( $F=3.9, p$ $<.001)$.

\subsection{Sedentary (Sitting) Behavior}

The daily number of minutes spent sitting were highest among residents of high-walkability/high-SES neighborhood (514 minutes per day). Sedentary time was lowest in the high walkability/low-SES neighborhood. Sedentary behavior among residents in the high-walkability/high-SES neighborhood was significantly different from all other neighborhoods ( $F=12.1, \mathrm{p}<.001)$.

\subsection{Weight Status}

Mean BMI was $24.6( \pm 5.7) \mathrm{kg} / \mathrm{m}^{2}$. Self-reported BMI was highest (mean $\left.=26 \mathrm{~kg} / \mathrm{m}^{2}\right)$ among residents in the high-walkability/high-SES neighborhood and least in the two low-SES neighborhoods (mean = 23.5 $\left.\mathrm{kg} / \mathrm{m}^{2}\right)$.

\section{Discussion}

This study is among the first to examine neighborhood-level BE features, walkability, and domainspecific PA (transport, leisure) in India. Previous studies have demonstrated significant associations between individual BE features and PA, predominantly in developed countries. ${ }^{28}$ Findings from this study show significant differences across sampled neighborhoods in domain-specific PA. This study extends transportation research findings in an Indian context by suggesting that neighborhood-level differences in walkability and SES may impact levels of leisure PA, travel PA, and weight status of individuals. ${ }^{73}$

Transport PA was higher among low-SES populations, while high-SES populations reported greater leisure-time PA. Sedentary time and BMI were highest in high-walkable/high-SES neighborhoods. To our knowledge, there has been no study estimating neighborhood BE variables and PA prevalence in India. This study sought to provide a preliminary test of the oft-stated hypothesis that neighborhood walkability as defined by land use and community design, ${ }^{30,74,75}$ is related to PA and body weight in India.

It is important to situate the findings of this study in the context of urban health disparities and socioeconomic inequities in India. Rapid urbanization and growth of cities in India has produced has been 
marked by the lack of adequate infrastructure and urban growth management, as well as by sharp socioeconomic divisions are reflected in the quality of the urban environment. ${ }^{41,76,77}$ These inequalities in distribution of wealth and SES reflect glaring urban health inequities; urban poor face greater exposure to risky and unhealthy living conditions in India.

Studies have repeatedly found that low SES groups do insufficient leisure PA to benefit their health, regardless of how SES is measured (e.g., based on education, income or occupation, area of residence). ${ }^{78}$ Our findings show that the gap narrowed when walking for transport is included in indices of PA, but SES differences remained. This difference is consistent with previous transportation research that has found no differences in leisure walking but significant differences in walking for transport purposes between neighborhoods stratified by walkability and SES. ${ }^{79-82}$ Given the positive relationship between PA and health, these differences are important to examine in LMICs like India where NCDs are on a sharp rise.

Urban settings in LMICs like India are prone to heavy traffic, narrow roads, diminishing green spaces and parks, resulting in urban areas that are not conducive to PA (e.g., walking, bicycling) over and above the risks of traffic accidents and pedestrian injuries they pose. ${ }^{43,67,76}$ In several cities in India, including Chennai, parks and green spaces are being destroyed to make way for housing and infrastructure to accommodate the growing population, ${ }^{83}$ thus limiting access to places for leisure PA. Low-SES neighborhoods in India are frequently overcrowded with high density of slum settlements without any planned open spaces such as parks or playgrounds. ${ }^{83}$

Residential density and land use mix are key measures of urban development patterns. ${ }^{46,63}$ Studies have shown that high density and availability of mixed or diverse land uses is associated with increased PA, ${ }^{84}$ and in particular increased walking for transport. ${ }^{75,85,86}$ Findings from this study show that by providing a mix of commercial facilities or non-residential land uses (e.g., restaurants, grocery or convenience stores, markets, retail, and shopping) and residential housing, residents are able to walk to multiple nearhome destinations. ${ }^{87}, 88$ In this study, low-SES neighborhoods were the densest, which can be attributed to overcrowding of affordable housing units, slum dwellings, and squatter settlements. ${ }^{48}$ Residents in these neighborhoods reported higher levels of transport PA compared to residents in high-SES neighborhoods. Residents in high-walkability/high-SES neighborhoods reported the highest levels of land-use mix diversity, but lower levels of transport-related walking compared to low-SES neighborhoods. Reasons for this may be lower levels of motor vehicle ownership among low-SES populations. For individuals in lowSES neighborhoods that live below the poverty level in this study, walking and bicycling are likely a necessity, thus explaining their greater levels of transport PA. Participants' workplace and home may also be proximate within walking/ bicycling distance to each other, boosting their transport PA. These results affirm SES differences in active transportation observed in previous research, with higher levels often found in the most socio-economically deprived groups. ${ }^{89}$

Contrary to usual transport PA patterns, SES variations in levels of total leisure PA and leisure MVPA across the four neighborhoods were in the opposite direction, suggesting that engagement in leisure-time MVPA was more prevalent in higher income groups. In the high-walkability neighborhoods (quadrants 1 \& 3), high-SES residents reported 50 more minutes of leisure MVPA than low-income residents, which may be attributed to greater access to BE facilities conducive for PA (gyms, recreation centers, parks, 
etc.) among high-SES participants. Previous research has highlighted that low-SES populations face barriers such as limited time, access to resources, and BE avenues for leisure-time PA. For example, parks and green spaces account for $60 \%$ of overall MVPA in high income countries. ${ }^{90}$ However, studies have shown that low-SES neighborhoods are less likely to have available facilities and locations to facilitate PA, such as parks and green spaces. ${ }^{91}$

Total MVPA and all PA levels were greatest among residents in the low-walkability/low-SES neighborhood, implying active lifestyles. The average resident in a low-SES neighborhood may be meeting the recommended PA guidelines of at least 150 minutes of PA per week, with transport PA being the primary contributor. In high-SES neighborhoods, leisure-time PA was the maximum contributor to total PA. Overall, these estimates of PA across leisure and transport domains are consistent with previous research in LMICs such as Nigeria ${ }^{38}$ and Brazil ${ }^{92,}{ }^{93}$, that have shown poorer individuals tend to walk more for utilitarian purposes (e.g., going to work or shopping) and less for leisure and recreation. In addition, low-SES populations may also have less awareness and knowledge about benefits of PA. Data from a recent study in South India underscored that an understanding of the benefits of PA may be underdeveloped in local populations, indicating education may be an important component of any PA policy in India. ${ }^{94}$ Overall, results from this study highlight income inequalities in leisure PA in low-SES neighborhoods in Chennai.

Perceptions of BE infrastructure may be subject to bias (i.e., physically active participants may be noticing more activity-friendly BE features, low-SES residents unaware of BE elements for PA). This may be a reason for residents in the high-walkability/low-SES neighborhood reporting greater walking/bicycling infrastructure. Residents in these neighborhoods may have limited knowledge and awareness of BE features, and thus likely to over report presence of BE supports (sidewalks, crosswalks, etc.) that are known to promote PA behaviors. Notably, safety from traffic was highest in the lowwalkability/low SES neighborhood, indicating that these neighborhoods had lower volume of traffic at reduced speed. Some BE differences between neighborhoods could be subtle because of geographic proximity and shared governance.

Significant differences in sedentary time across neighborhoods indicated high-SES participants spent more time sitting in a week, in comparison with low-SES participants. Increased time spent in sedentary activities is known to be a risk marker for obesity in high-income populations. ${ }^{95,}{ }^{96}$ Residents of high-SES neighborhoods also had higher BMI (means $=26.0$ and $24.3 \mathrm{~kg} / \mathrm{m}^{2}$ ), with greater percentages of obese participants $(16.5 \%, 15.2 \%)$. Studies in LMICs have shown high-SES populations were more likely to be obese. ${ }^{97,}{ }^{98}$ Findings of this study are consistent with previous research where high income populations have reported prolonged computer/TV use, hours of sitting at work, and sedentary travel time. ${ }^{97,99}$ Levels of LTPA were greater among high-SES participants, indicating their engagement in PA may be primarily occurring during structured leisure-time, while the rest of their day involved lengthy sitting times.

Explanations for these shifts in PA patterns and sedentary time are multi-faceted and complex in India, including several cultural, social, and environmental factors. Rapid urbanization, increased mechanization, and technological advancements have altered quality of life to a great extent in India. Socioeconomic changes have improved living conditions and standard of living in the last decade. In high-SES populations in India, the dependence on the automobile is apparent as ordinary, everyday tasks 
such as a trip to the corner store, coffee shop, getting to school or work that used to be completed on foot, are now accomplished by driving to those destinations in privately owned cars. ${ }^{76,100}$ The availability of new technologies and electronic devices (e.g., televisions, computers, electronic entertainment, the internet, and wireless communication devices) has enabled people to reduce the amount of physical labor needed to accomplish many tasks in their daily lives. ${ }^{6}$ The pervasive nature of technology, proliferation of new devices, and the transition from the traditional physically demanding agricultural and industrial employment to mechanized manufacturing processes has altered patterns of movement and energy expenditure at home, work, during leisure, and travel in India. ${ }^{101}$ Over the last century, technological advances and outsourcing of labor-intensive manufacturing in the developed world have created more sedentary desk jobs in several LMICs including India.

It is important to note several socioeconomic differences in shifting PA patterns. As a result of increasingly common sedentary jobs, PA in high-SES populations in India has become largely recreational, taking place during leisure time as budgets and time allow in public parks, gyms, and private recreation centers. ${ }^{102}$ In low-SES populations, our findings are consistent with previous research that indicates residents in poorer neighborhoods may have limited ability to engage in leisure PA in the face of inaccessible environments. ${ }^{100}$ In several LMICs, low-SES people often confront difficult social and environmental barriers to PA such as lack of efficient transportation choices, unsafe neighborhoods and traffic conditions, poor access to parks and recreational facilities, air pollution, lack of time, poor health and lack of social support for exercise..$^{59,103}$

Inadequate housing, lack of educational and employment opportunities, and unsafe working conditions are other socioeconomic conditions commonly confronted by low-SES populations that contribute to inequitable health outcomes. In India, while many of these barriers also exist for other income groups, they often exist to a greater degree in low-SES communities who also have less means to overcome them than other income groups. Low-SES populations are also less able financially to choose more PA-friendly alternatives such as living closer to work or in a safer and cleaner neighborhood, purchasing a gym membership, paying a fee to visit the community pool or recreation center, or purchasing services that afford time for PA such as housecleaning or childcare. ${ }^{78,104-106}$

As obesity becomes more prevalent in LMICs, and populations become more urban, it is important that future studies understand energy expenditure patterns and their relationship to obesity. Saelens at al. (2003) suggest that a 70-minute-per-week difference in PA translates to walking 3 miles more per week given an approximate 20-minute-per-mile pace. Over the course of a year, this amount of walking would yield about 15000 kilocalories of energy expenditure for a 68-kilogram person, which, if not offset by caloric intake, could result in almost 1.8 kilograms of weight loss. Prolonged sedentary behaviors are known to mediate relationships between neighborhood walkability and overweight/obesity. ${ }^{95}$ Future research could examine how these prevalent and often prolonged sedentary behaviors mediate relationships between neighborhood walkability and overweight/obesity in India.

This study has several limitations. The cross-sectional study design limits causal inference and the relatively small sample from a single city in India may limit generalizability. ${ }^{107}$ Neighborhoods were selected to increase variability in walkability and SES, but this was not adjusted for in statistical models. There remains the possibility of residual confounding. Due to time, budget, and resource constraints, this 
study did not capture any objective data and is only based on subjective perceptions of the BE and participants' self-report PA levels. Objective data on BEs (e.g., GIS measures) and PA (e.g., accelerometers) is scarce in India and was unavailable for the neighborhoods sampled in this study. Selfreported PA from IPAQ and neighborhood measures like NEWS-India are subject to bias (e.g., overestimation of PA; social desirability of PA; physically active people may notice more BE infrastructure and neighborhood destinations). ${ }^{108}$ Duration of PA is based on self-report, prone to recall bias, and likely over estimates rates of PA. A limitation of this study and PA literature in general is a lack of consensus on measuring domain-specific PA in LMICs (e.g., lack of tested items, inadequate details on types of PA). IPAQ modules to capture leisure and transport PA have not been validated in India.

As a result of mechanization and urbanization, PA in high income countries has become structured and mostly occurring during leisure-time in environments (e.g., parks, recreation centers, and gymnasiums) designed for it. ${ }^{109}$ In contrast, PA among LMIC populations is unstructured and occurs as a part of everyday life. Physically intensive activities may be intersecting domestic, occupational, and travel domains in the daily routines of LMIC populations, making it difficult to disentangle independent effects. For example, activities requiring energy expenditure at home (cleaning, gardening), at work (farming, physically demanding labor), and when traveling (walking, bicycling), are often mixed in everyday lifestyle of LMIC populations. In addition, differences in culture and social context of everyday life (e.g., social stigmas attached to walking, use of the car as a social status symbol, attitudes towards women in public spaces, etc.) may impact levels of utilitarian PA (e.g., walking or bicycling to work, school), and may not be adequately captured by IPAQ domains.

Household PA was not measured in this study, which is another limitation. Household PA in some LMICs like India in divided along gender lines, and may be significant contributor to total PA, particularly among housewives and the unemployed. ${ }^{110}$ The traditional role of women in assuming responsibility for a majority of the household work, as caregivers, and supporting other members of the households, may limit the amount of time available for leisure PA activities. Cultural expectations, beliefs, and norms may also restrict the participation of women in certain forms of PA among some religious and ethnic groups. ${ }^{110}$ Expanding the definition of PA to include household and occupational activities, in addition to the leisure and transport domains, as well as an understanding of where these PA types occur, is necessary to gain a complete understanding of BE-PA relationships in India.

Although this study was based on relatively small samples at the neighborhood level, it may be the first to measure and document BE features and PA levels in India. Differences in domain-specific PA in India suggest that measuring only leisure-time PA, as most studies in the developed countries have done, may underestimate levels of total PA in LMICs. This necessitates examination of all-domain PA (household, occupational, travel, and leisure) and relationships with BE in LMICs. It is important that future studies develop neighborhood walkability and PA measures unique to India based on empirical analysis.

The SES differences in PA patterns highlight the need to lower community barriers to PA and design street infrastructure to promote PA as part of everyday life. By promoting active living - a way of life that integrates PA into daily routines - urban design and transportation planning tools can create in healthenhancing attributes in the BE, while also considering air pollution exposure. ${ }^{111,112}$ Examples include active transportation "green” corridors that are separated from major traffic arteries, design of dense, 
walkable neighborhoods with a mix of land uses, serving communities with public transit, and incentives to reduce congestion, parking, and emissions in urban centers. ${ }^{113}$ It is imperative that future research in India and other LMICs explore urban design approaches for active living tailored to the cultural, social, and environmental contexts.

\section{Conclusion}

Urban areas in India are growing rapidly in population. As India becomes more urban, the impact on PA, sedentary behaviors, and weight status should be assessed. This project advances the current state of urban planning and public health research by identifying neighborhood-level differences in $\mathrm{BE}$ characteristics, domain-specific PA, and weight status in urban India. An understanding of BE correlates of primary PA domains (transport, leisure) can support the development of contextually tailored interventions to reverse the determinants of inactivity occurring through patterns of urbanization and sedentary behaviors in India. Initiatives to reduce chronic disease risk among residents living in neighborhoods of differing income and walkability should include a focus on reducing TV viewing time and other sedentary behaviors and enacting policies that can lead to the development or redevelopment of more-walkable neighborhoods. Additional research is needed to advance measurement and evaluation of BE's and PA in India.

While this is first-generation research in India, findings have the potential to guide design decisions for healthy living in urban Indian neighborhoods. Solutions to improve health through transportation include designing urban environments to facilitate active living, a way of life that integrates PA into daily routines. ${ }^{114,115}$ By analyzing how health outcomes are part of the complexity of urban processes, this project draws attention to the role that urban planning and transport policies can and should play in delivering public health improvements through reshaping the fabric of Indian cities.

\section{Acknowledgements}

Deepti Adlakha was funded by the International Field Dissertation Research Award at the Brown School, Washington University in St. Louis. The content is solely the responsibility of the authors and does not necessarily represent the official views of Washington University in St. Louis. The authors would like to thank Dr. James F. Sallis, Dr. Rodrigo S, Reis, and members of the IPEN Coordinating Center at University of California, San Diego, for their assistance with study protocols and implementation of NEWS-India. The authors wish to acknowledge the following research assistants' support in translation and data collection: Priyadarshini Chidambaram, Avinash Ramu, S. Gayathri, R. Dhivya, Gomathi Srinivasan, V. Sridevi, and Shanthi.

\section{References}

1. UNFPA. State of World Population 2015. 2015.

2. Ranasinghe $C$, Ranasinghe $P$, Jayawardena $R$, Misra $A$. Physical activity patterns among SouthAsian adults: a systematic review. Int. J. Behav. Nutr. Phys. Act. 2013;10(1):116.

3. Jonas JB, Panda-Jonas S, Nangia V, Joshi PP, Matin A. Diabetes Mellitus in Rural India. Epidemiology 2010;21(5):754-755

4. Mohan V, Pradeepa R. Mortality in diabetes mellitus: revisiting the data from a developing region of the world. Postgrad Med J 2009;85(1003):225-6.

5. Pradeepa R, Mohan V. The changing scenario of the diabetes epidemic: implications for India. Indian Journal of Medical Research 2002;116:121-132. 
6. Hallal PC, Andersen LB, Bull FC, Guthold R, Haskell W, Ekelund U. Global physical activity levels: surveillance progress, pitfalls, and prospects. The Lancet 2012;380(9838):247-257.

7. World Health Organization. Global Burden of Disease Study 2010 (GBD 2010). Geneva, Switzerland: WHO; 2012.

8. Pearson TA. Cardiovascular disease in developing countries: myths, realities, and opportunities. Cardiovasc Drugs Ther 1999;13(2):95-104.

9. Pearson TA. Cardiovascular diseases as a growing health problem in developing countries: the role of nutrition in the epidemiologic transition. Public Health Reviews 1996;24(2):131-46.

10. Woodcock J, Banister D, Edwards P, Prentice AM, Roberts I. Energy and transport. The Lancet 2007;370(9592):1078-1088.

11. World Health Organization. Obesity: Preventing and Managing the Global Epidemic. WHO Technical Report Series 894. Geneva, Switzerland: World Health Organization; 2000.

12. World Health Organization. Global status report on noncommunicable diseases 2011

13. United Nations Organization. The Millennium Development Goals Report. In. Geneva,

Switzerland: United Nations Organization; 2011.

14. Sallis JF, Floyd MF, Rodriguez DA, Saelens BE. Role of built environments in physical activity, obesity, and cardiovascular disease. Circulation 2012;125(5):729-37.

15. Kerr J, Sallis JF, Owen N, De Bourdeaudhuij I, Cerin E, Sugiyama T, et al. Advancing science and policy through a coordinated international study of physical activity and built environments: IPEN adult methods. J Phys Act Health 2013;10(4):581-601.

16. Sallis JF, Cerin E, Conway TL, Adams MA, Frank LD, Pratt M, et al. Physical activity in relation to urban environments in 14 cities worldwide: a cross-sectional study. The Lancet 2016;387(10034):22072217.

17. Stokols D. Establishing and maintaining healthy environments. Toward a social ecology of health promotion. Am Psychol 1992;47(1):6-22.

18. Sallis JF, Cervero RB, Ascher W, Henderson KA, KraftMK, Kerr J. An ecological approach to creating active living communities. Annu Rev Public Health 2006;27:297-322.

19. Sallis JF, Owen N, Fisher EB. Ecological models of health behavior. In: Glanz K, Rimer BK, Viswanath K, editors. Health Behavior and Health Education: Theory, Research and Practice. Fourth ed. San Francisco: Jossey-Bass; 2008. p. 464-485.

20. Saelens BE, Sallis JF, Frank LD. Environmental correlates of walking and cycling: Findings from the transportation, urban design and planning literatures. Ann. Behav. Med. 2003;25(2):80-91.

21. Papas MA, Alberg AJ, Ewing R, Helzlsouer KJ, Gary TL, Klassen AC. The built environment and obesity. Epidemiologic Reviews 2007;29(1):129-43.

22. Sallis JF, Glanz K. The role of built environments in physical activity, eating, and obesity in childhood. Future Child 2006;16(1):89-108.

23. Hipp JA, Adlakha D, Eyler A, Chang B, Pless R. Emerging Technologies: Webcams and CrowdSourcing to Identify Active Transportation. American Journal of Preventive Medicine 2013;44(1):96-97.

24. Adlakha D, Budd EL, Gernes R, Sequeira S, Hipp JA. Use of emerging technologies to assess differences in outdoor physical activity in St. Louis, Missouri. Frontiers in Public Health 2014;2(41).

25. Brownson RC, Hoehner CM, Day K, Forsyth A, Sallis JF. Measuring the Built Environment for Physical Activity: State of the Science. American Journal of Preventive Medicine 2009;36(4 Supplement):S99-123.e12.

26. Brownson RC, Haire-Joshu D, Luke DA. Shaping the context of health: A Review of Environmental and Policy Approaches in the Prevention of Chronic Diseases. Annual Review of Public Health 2006;27(1):341-370. 
27. Committee on physical activity; health; transportation; and land use. Does the built environment influence physical activity? Examining the evidence. Washington, D.C.: Transportation Research Board, Institute of Medicine; 2005.

28. Sallis JF, Bowles HR, Bauman A, Ainsworth BE, Bull FC, Craig CL, et al. Neighborhood environments and physical activity among adults in 11 countries. Am. J. Prev. Med. 2009;36:484 - 490. 29. Adlakha D, Hipp AJ, Marx C, Yang L, Tabak R, Dodson EA, et al. Home and Workplace Built Environment Supports for Physical Activity. American Journal of Preventive Medicine 2014;48(1):104107.

30. Handy S, Boarnet M, Ewing R, Killingsworth R. How the built environment affects physical activity: views from urban planning. Am J Prev Med 2002;23:64 - 73.

31. Badland HM, Schofield GM, Garrett N. Travel behavior and objectively measured urban design variables: Associations for adults traveling to work. Health \& Place 2008;14(1):85-95.

32. Yang L, Hipp JA, Adlakha D, Marx CM, Tabak RG, Brownson RC. Choice of commuting mode among employees: Do home neighborhood environment, worksite neighborhood environment, and worksite policy and supports matter? Journal of Transport \& Health 2015;2(2):212-218.

33. Marshall J, Brauer M, Frank L. Healthy Neighborhoods: Walkability and Air Pollution. Environ Health Perspect 2009;117:1752-1759.

34. Ewing R, Meakins G, Hamidi S, Nelson A. Relationship Between Urban Sprawl and Physical Activity, Obesity, and Morbidity. American Journal of Health Promotion 2003;18(1):47-57.

35. Prentice AM. The emerging epidemic of obesity in developing countries. International Journal of Epidemiology 2006;35(1):93-99.

36. Milton K, Macniven R, Bauman A. Review of the epidemiological evidence for physical activity and health from low- and middle-income countries. Global Public Health 2014;9(4):369-81.

37. Sallis J. Environmental and policy research on physical activity is going global. Res. Exerc. Epidemiol. 2011;13:111 - 117.

38. Oyeyemi AL, Sallis JF, Deforche B, Oyeyemi AY, De Bourdeaudhuij I, Van Dyck D. Evaluation of the neighborhood environment walkability scale in Nigeria. International Journal of Health Geographics 2013;12:16.

39. Guha R. India After Gandhi: The History of the World's Largest Democracy. Pan Macmillan; 2011. 40. Goenka S. Powering India's Growth. Public Health Foundation of India, Centre for Chronic Disease Control, World Health Organization. Country Office for India. Initiative for Cardiovascular Health Research in the Developing Countries; 2007.

41. Gupta R. The Pattern of Urban Land-use Changes: A Case Study of the Indian Cities. Environment and Urbanization Asia 2014;5(1):83-104.

42. World Health Organization. Global status report on road safety Geneva, Switzerland; 2013.

43. World Health Organization. Making Walking Safe: A brief overview of pedestrian safety around the world. Geneva, Switzerland; 2013.

44. World Health Organization. Pedestrian safety: A road safety manual for decision-makers and practitioners Geneva, Switzerland: World Health Organization; 2013.

45. Sahni S, Aulakh RS. Planning for Low Carbon Cities in India. Environment and Urbanization Asia 2014;5(1):17-34.

46. Saelens BE, Sallis JF. Neighborhood Environment Walkability Scale (NEWS). 2002; Available from: http://sallis.ucsd.edu/measure news.html

47. Saelens BE, Sallis JF, Black JB, Chen D. Neighborhood-Based Differences in Physical Activity: An Environment Scale Evaluation. American Journal of Public Health 2003;93(9):1552-58.

48. Vēnkațācalapati Āl, Aravindan R. Chennai Not Madras: Perspectives on the City. Mumbai: Marg Publications and National Centre for the Performing Arts, Mumbai, India; 2006.

49. Hancock ME. The Politics of Heritage from Madras to Chennai. Indiana University Press; 2008. 
50. Ministry of Home Affairs. Census of India 2011. New Delhi, India: Government of India; 2013. 51. Ministry of Urban Development (MOUD). Level of Urbanization. New Delhi, India: Government of India; 2013.

52. Gupta S, Singh Z, Purty A, Kar M, Vedapriya D, Mahajan P, et al. Diabetes prevalence and its risk factors in rural area of Tamil Nadu. Indian Journal of Community Medicine 2010;35(3):396-399.

53. Foster KA, Hipp JA. Defining Neighborhood Boundaries for Social Measurement: Advancing Social Work Research. Social Work Research 2011;35(1):25-35.

54. Frank LD, Sallis JF, Saelens BE, Leary L, Cain K, Conway TL, et al. The development of a walkability index: application to the Neighborhood Quality of Life Study. Br J Sports Med 2010;44:924 - 933.

55. Turrell G. Income non-reporting: implications for health inequalities research. J Epidemiol Community Health 2000;54(3):207-14.

56. Cerin E, Conway TL, Saelens BE, Frank LD, Sallis JF. Cross-validation of the factorial structure of the Neighborhood Environment Walkability Scale (NEWS) and its abbreviated form (NEWS-A). Int. J. Behav. Nutr. Phys. Act. 2009;6(1):32.

57. Cerin E, Conway TL, Cain KL, Kerr J, De Bourdeaudhuij I, Owen N, et al. Sharing good NEWS across the world: developing comparable scores across 12 countries for the Neighborhood Environment Walkability Scale (NEWS). BMC Public Health 2013;13:309.

58. Kocher J, Lerner M. Walk Score. In. Seattle, WA.: Walk Score; 2007.

59. Parra DC, Hoehner CM, Hallal PC, Ribeiro IC, Reis RS, Brownson RC, et al. Perceived environmental correlates of physical activity for leisure and transportation in Curitiba, Brazil. Prev Med 2011;52(3-4):234-8.

60. Cerin E, Sit C, Cheung M, Ho S, Lee L, Chan W. Reliable and valid NEWS for Chinese seniors: measuring perceived neighborhood attributes related to walking. Int. J. Behav. Nutr. Phys. Act. 2010;7(84).

61. Saelens BE, Sallis JF, Black JB, Chen D. Neighborhood-based differences in physical activity: an environment scale evaluation. Am J Public Health 2003;93:1552 - 1558.

62. Cohen J. Statistical Power Analysis for the Behavioral Sciences. 2nd ed: Lawrence Erlbaum Associates.; 1988.

63. Cerin E, Saelens BE, Sallis JF, Frank LD. Neighborhood Environment Walkability Scale: validity and development of a short form. Medicine \& Science in Sports \& Exercise 2006;38(9):1682-91.

64. Sallis J, DeBourdeaudhuij I, Owen N. International Physical Activity and the Environment Network. In. Mainz, Germany: International Congress of Behavioral Medicine; 2004.

65. De Bourdeaudhuij I, Sallis JF, Saelens BE. Environmental correlates of physical activity in a sample of Belgian adults. Am J Health Promot 2003;18(1):83-92.

66. Malavasi LdM, Duarte MdFdS, Both J, Reis RS. Neighborhood walkability scale (News - Brazil): Back translation and Reliability. Braz. J. Kinanthropom. Human Perform. 2007;9(4):339-350.

67. Adlakha D, Hipp JA, Brownson RC. Adaptation and Evaluation of the Neighborhood Environment Walkability Scale in India (NEWS-India). International Journal of Environmental Research and Public Health 2016;13(4).

68. Cerin E, Saelens BE, Sallis JF, Frank LD. Neighborhood environment walkability Scale: validity and development of a short form. Med Sci Sports Exerc 2006;38:1682 - 1691.

69. IPAQ. International physical activity questionnaires. IPAQ-long: last 7 days self-administered format. In: International physical activity questionnaires; 2002.

70. Craig CL, Marshall AL, Sjostrom M. International physical activity questionnaire: 12-country reliability and validity. Med Sci Sports Exerc 2003;35(8):1381 - 1395.

71. Vandelanotte C, Bourdeaudhuij ID, Philippaerts RM, Sjöström M, Sallis JF. Reliability and Validity of a Computerized and Dutch Version of the International Physical Activity Questionnaire (IPAQ) J Phys Act Health $2005 ; 2(1): 63-75$. 
72. IBM Corp. IBM SPSS Statistics for Windows, Version 22.0. In. Armonk, NY: IBM Corp.; Released 2012.

73. Saelens BE, Sallis JF, Frank LD. Environmental correlates of walking and cycling: findings from the transportation, urban design, and planning literatures. Ann Behav Med 2003;25:80 - 91.

74. Chen DD. The science of smart growth. Sci Am 2000;286(6):84-91.

75. Frank LD. Land Use and Transportation Interaction: Implications on Public Health and Quality of Life. J. Plan. Educ. Res. 2000;20(1):6-22.

76. Solanki HK, Ahamed F, Gupta SK, Nongkynrih B. Road Transport in Urban India: Its Implications on Health. Indian Journal of Community Medicine : Official Publication of Indian Association of Preventive \& Social Medicine 2016;41(1):16-22.

77. Ministry of Urban Development (MOUD). Urban Infrastructure: Twelfth Five Year Plan (20122017). New Delhi, India: Government of India; 2013.

78. Giles-Corti B, Donovan RJ. Socioeconomic status differences in recreational physical activity levels and real and perceived access to a supportive physical environment. Preventive Medicine 2002;35(6):601-11.

79. Ewing R, Cervero R. Travel and the Built Environment. J Am Plan Assoc 2010;76:265 - 294.

80. Handy S. Methodologies for exploring the link between urban form and travel behavior. Transportation Research Part D: Transport and Environment 1996;1(2):151-165.

81. Sallis JF, Saelens BE, Frank LD, Conway TL, Slymen DJ, Cain KL, et al. Neighborhood built environment and income: examining multiple health outcomes. Soc Sci Med 2009;68:1285 - 1293.

82. Bauman AE, Reis RS, Sallis JF, Wells JC, Loos RJF, Martin BW. Correlates of physical activity: why are some people physically active and others not? The Lancet 2013;380(9838):258-271.

83. Vishwanath T, Lall SV, Dowall D, Lozano-Gracia N, Sharma S, Wang HG. Urbanization beyond municipal boundaries: nurturing metropolitan economies and connecting peri-urban areas in India Washington, DC The World Bank; 2013.

84. Kirk SF, Penney TL, McHugh TL. Characterizing the obesogenic environment: the state of the evidence with directions for future research. Obes. Rev. 2010;11(2):109-17.

85. Cervero R, Kockelman K. Travel demand and the 3Ds: Density, diversity, and design. Transportation Research Part D-Transport and Environment 1997;2(3):199-219.

86. Frank L, Sallis J, Conway T, Chapman J, Saelens B, Bachman W. Many pathways from land use to health: Associations between neighbourhood walkability and active transportation, body mass index, and air quality. J Am Plann Assoc 2006;72(1):75-87.

87. Brown BB, Yamada I, Smith KR, Zick CD, Kowaleski-Jones L, Fan JX. Mixed land use and walkability: Variations in land use measures and relationships with BMI, overweight, and obesity. Health \& Place 2009;15(4):1130-1141.

88. Duncan M, Winkler E, Sugiyama T, Cerin E, duToit L, Leslie E, et al. Relationships of Land Use Mix with Walking for Transport: Do Land Uses and Geographical Scale Matter? Journal of Urban Health 2010;87(5):782-795.

89. Rind E, Shortt N, Mitchell R, Richardson EA, Pearce J. Are income-related differences in active travel associated with physical environmental characteristics? A multi-level ecological approach. The International Journal of Behavioral Nutrition and Physical Activity 2015;12:73.

90. Cohen DA, Marsh T, Williamson S, Derose KP, Martinez H, Setodji C, et al. Parks and physical activity: Why are some parks used more than others? Preventive Medicine 2010;50(Supplement 1):S9S12.

91. Pearce J, Witten, K., Hiscock, R., Blakely, T. Are socially disadvantaged neighbourhoods deprived of health-related community resources? International Journal of Epidemiology 2007;36:348-355. 
92. Cervero R, Sarmiento OL, Jacoby E, Gomez LF, Neiman A. Influences of Built Environments on Walking and Cycling: Lessons from Bogotá. International Journal of Sustainable Transportation 2009;3(4):203-226.

93. Gomez LF, Sarmiento OL, Parra DC, Schmid TL, Pratt M, Jacoby E, et al. Characteristics of the built environment associated with leisure-time physical activity among adults in Bogota, Colombia: a multilevel study. J Phys Act Health 2010;7 Suppl 2:S196-203.

94. Veluswamy SK, Maiya AG, Nair S, Guddattu V, Nair NS, Vidyasagar S. Awareness of chronic disease related health benefits of physical activity among residents of a rural South Indian region: a cross-sectional study. Int J Behav Nutr Phys Act 2014;11(1):1479-5868.

95. Kozo J, Sallis JF, Conway TL, Kerr J, Cain K, Saelens BE, et al. Sedentary behaviors of adults in relation to neighborhood walkability and income. Health Psychol 2012;31(6):704-13.

96. Pampel FC, Denney JT, Krueger PM. Obesity, SES, and economic development: a test of the reversal hypothesis. Soc Sci Med 2012;74(7):1073-81.

97. Ng SW, Popkin BM. Time use and physical activity: a shift away from movement across the globe. Obesity Reviews 2012;13(8):659-680.

98. Salmon J, Owen N, Crawford D, Bauman A, Sallis JF. Physical activity and sedentary behavior: a population-based study of barriers, enjoyment, and preference. 2003;22(2):178-88.

99. Sisson SB, Camhi SM, Church TS, Martin CK, Tudor-Locke C, Bouchard C, et al. Leisure time sedentary behavior, occupational/domestic physical activity, and metabolic syndrome in U.S. men and women. Metab Syndr Relat Disord 2009;7(6):529-36.

100. Adlakha D, Hipp JA, Brownson RC, Eyler A, Lesorogol C, Raghavan R. "Can we walk?" environmental supports for physical activity in India. Preventive Medicine 2016; In press.

101. Popkin BM. Urbanization, lifestyle changes and the nutrition transition. World Development 1999;27(11):1905-1916.

102. Heath GW, Parra DC, Sarmiento OL, Andersen LB, Owen N, Goenka S, et al. Evidence-based intervention in physical activity: lessons from around the world. The Lancet 2012;380(9838):272-281.

103. Reis RS, Hino AA, Parra DC, Hallal PC, Brownson RC. Bicycling and walking for transportation in three Brazilian cities. Am JPrev Med 2013;44(2):e9-17.

104. Fermino R, Reis RS, Hallal PC, Kaczynski AT. Who are the Users of Urban Parks? A Study With Adults From Curitiba, Brazil. J Phys Act Health 2014.

105. Hallal PC, Azevedo MR, Reichert FF, Siqueira FV, Araujo CL, Victora CG. Who, when, and how much? Epidemiology of walking in a middle-income country. Am J Prev Med 2005;28(2):156-61.

106. Kelly CM, Lian M, Struthers J, Kammrath A. Walking to Work: The Roles of Neighborhood Walkability and Socioeconomic Deprivation. J Phys Act Health 2013.

107. Glass TA, Goodman SN, Hernan MA, Samet JM. Causal inference in public health. Annu Rev Public Health 2013;34:61-75.

108. Montoye HJ. Measuring Physical Activity and Energy Expenditure. Human Kinetics; 1996.

109. Han B, Cohen DA, McKenzie TL. Quantifying the contribution of neighborhood parks to physical activity. Preventive Medicine 2013;57(5):483-487.

110. Chomitz VR, Prabhu SS, Thanikachalam S, Vijayakumar H, Chui KKH, Must A, et al. Physical activity and sedentary behavior in South Indian adults: Urbanicity, gender, and obesity The FASEB Journal 2013;27.

111. Giles-Corti B, Vernez-Moudon A, Reis R, Turrell G, Dannenberg AL, Badland H, et al. City planning and population health: a global challenge. The Lancet 2016.

112. Tainio M, de Nazelle AJ, Götschi T, Kahlmeier S, Rojas-Rueda D, Nieuwenhuijsen MJ, et al. Can air pollution negate the health benefits of cycling and walking? Preventive Medicine 2016;87:233-236. 113. James P, Hart JE, Laden F. Neighborhood walkability and particulate air pollution in a nationwide cohort of women. Environmental Research 2015;142:703-711. 
114. Barker DC, Gutman MA. Evaluation of Active Living Research: Ten Years of Progress in Building a New Field. American Journal of Preventive Medicine 2014;46(2):208-215.

115. Edwards $P$, Tsouros AD. Promoting Physical Activity and Active Living in Urban Environments: The Role of Local Governments. WHO Regional Office for Europe; 2006.

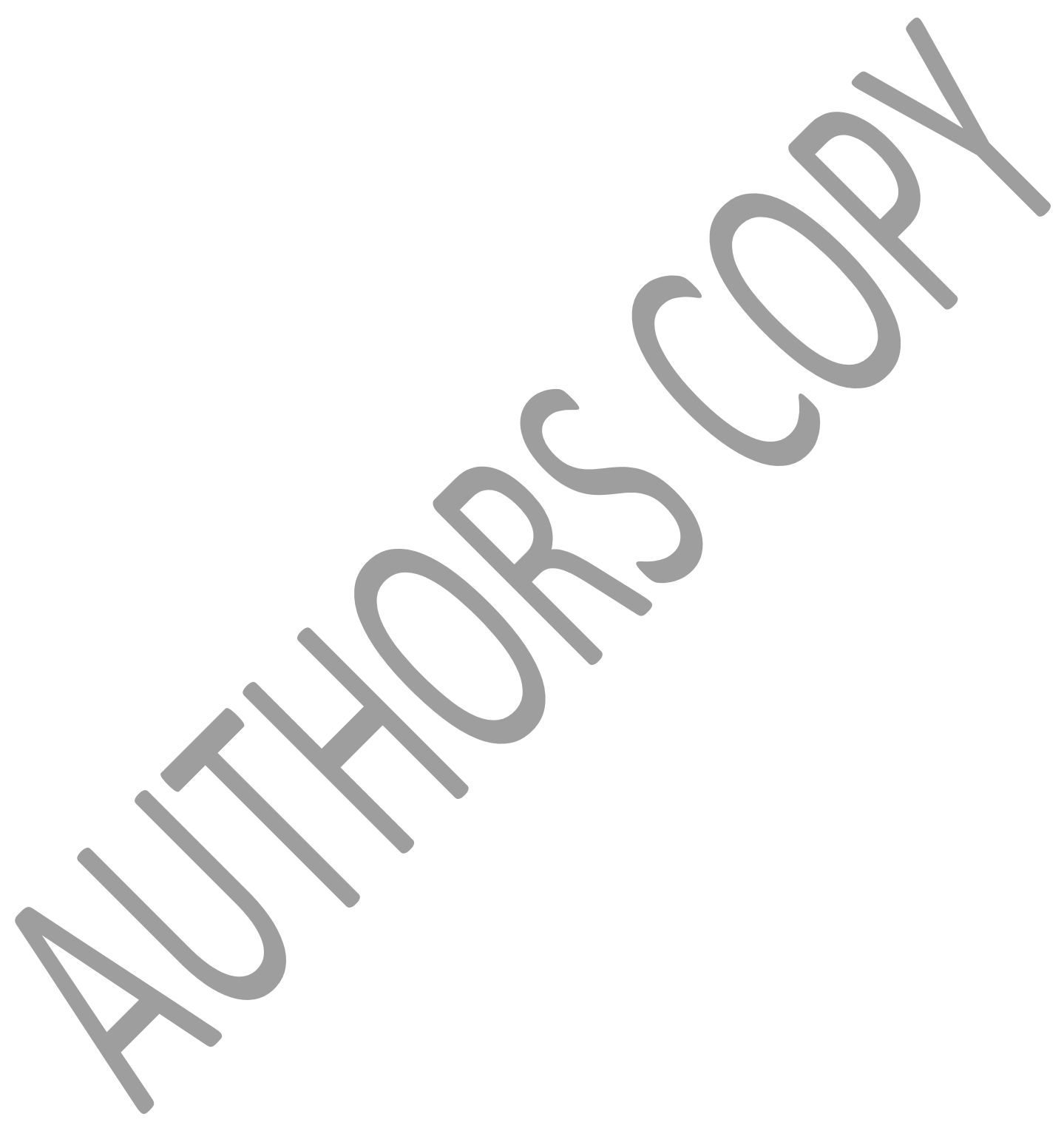

